\title{
Can Food Porn Make Us Slim? How Brains of Consumers React to Food in Digital Environments
}

\author{
Olivia Petit $^{1,2 *}$, Adrian D Cheok ${ }^{1,2}$ and Olivier Oullier ${ }^{3}$ \\ ${ }^{1}$ Imagineering Institute, Iskandar, Malaysia \\ ${ }^{2}$ City University London, UK \\ ${ }^{3}$ Aix-Marseille University and CNRS, LPC, UMR 7290, FED 3C, Behavior, Brain and Cognition Institute, FR 3512, Marseille, France
}

\begin{abstract}
People constantly publish/share their pictures/videos of delicious food dishes on social media. This excessive display of food pictures on Instagram, Facebook, Twitter, Snapchat, Pinterest, and other social media is often referred to as "food porn". Seeing food presented in an appetizing and/or "ready to be eaten" manner allows the brains of the viewer to vividly imagine the consumption experience related to eating what they see. Looking at pictures of food is known to trigger gustatory sensations in the brain, and to often triggering the desire to consume. As the food industry is using social media to promote their products, public health prevention and organizations in charge of promoting healthy lifestyles would be behooved to coincide their practices with this digital (r)evolution. This article discusses how multisensory mental simulation - i.e. the imagination of all the sensations associated with food consumption - via social media, can be used to produce satiety. In addition, making the consumption of healthy foods more appetizing and enjoyable to better regulate food intake.
\end{abstract}

\section{Introduction}

In OECD countries, the majority of the population and as many as one in five children are overweight or obese [1]. People with severe obesity (class 2; Body Mass Index (BMI): $35<\mathrm{BMI}<39.9$ ) die 8 to 10 years earlier than those with normal weight $(18.5<\mathrm{BMI}<24.9)$. Overall health spending on obese people is $25 \%$ higher than that on lean ones. The obesity rate is increasing faster in emerging countries, which have seen over-nourishment replacing under nourishment [2]. In countries where individuals are not controlling their diet, food intake and physical inactivity have added to the overall human, societal and financial burden of obesity [2].

Not only the rise of cheap high caloric food, but also the size of portions, increase the amount of food that people eat [3-5]. Zlatevska, Dubelaar and Holden [6] have shown in a meta-analysis that doubling portion size leads to an average of $35 \%$ increase in the amount consumed. It has been shown that the amount of food people eat depends more on the portion size rather than their level of hunger [4]. There is indeed a strong cultural effect in what individuals consider the right portion to eat and use (i.e. non-consciously the portions they consume at home serve as references) [7-8]. Unfortunately, more and more people consume meals that are prepared by the food industry than home-cooked ones. The former tend to be sold in the form of big portions of unhealthy food that therefore become the reference of what a portion size and content should be [3-5, 9-13].

Interestingly, food is no longer something that people share solely around a table, or via recipes they exchange with other people. With cable TV and social media, a new food sharing behavior has emerged: food porn (Figure 1). People enjoy viewing and sharing appetizing videos and pictures of food in many different ways [14-15]. For example, Good Food's Instagram [16] has more than 50k followers that can use it as a way to know what the most popular dishes are. It also reveals that food is now presented as something that will be "taking over Instagram" rather than something that will end up in plates [15]. The pleasure of viewing food on a screen now even exceeds the pleasure associated with seeing real food; particularly in the case of obese people[15,17]. Spence et al. [15] highlight that: People in the mature economies are watching more cookery shows on TV than ever before [18-21]. They also report that the amount of hours spent watching TV significantly influences the energy intake, which is positively correlated with one's body-mass index [22-23]. Thus, people are both surrounded by food products in retail stores, food pictures on social media, and eating opportunities. All together these stimuli have a tremendous impact on obesity [15].

Innovative ways are required to help people make healthy food choices and reduce the amount of food consumed, despite being offered large portions [24]. In the age of digital food networks (social media), we advocate that multisensory mental imagery - such as imagining the smell, taste, and temperature of the food while eating [25], can be an effective way for consumers to regulate their food intake. Indeed, multisensory mental imagery can play a key role in people's subsequent food-related behaviors $[25,26]$. Based on previous research, in this article we deal with the following points (1) we offer a summary of the main effects on multisensory mental imagery on food craving, (2) satiety, (3) unhealthy food portion regulation, (4) and healthy food choice. Finally, we suggest (5) some directions to improve food-related

Correspondence to: Olivia Petit, Imagineering Institute, Medini Mall in Nusajaya City, Iskandar, Malaysia, Tel: +60 750967 41; E-mail: oliviapetit@imagineeringinstitute.org

Key words: Food porn, multisensory mental imagery, consumer behavior, health prevention, social media, digital communication, neuromarketing

Received: December 31, 2015; Accepted: January 11, 2016; Published: April 15 2016 


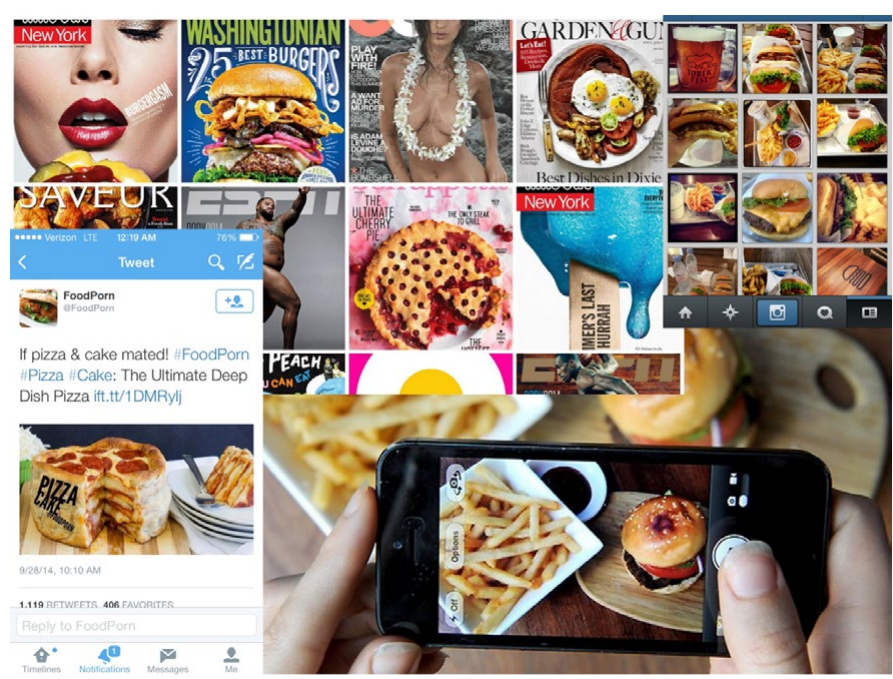

Figure 1. Food porn on social media.

multisensory mental imagery in digital environments thanks to new technologies such as virtual reality and digital sensory technologies.

\section{Multisensory mental imagery and food craving}

When people eat chocolate, the brain encodes, integrates, and coordinates all the different sensory signals related to its consumption: How it looks, what it feels like when people bite into it, what it tastes like on the tongue, how it smells, etc. When people are later exposed to chocolate pictures, they mentally simulate prior perceptions and experiences associated with its consumption, leading to activity in many of the same sensory regions and networks of the brain that are active during food perception and consumption $[27,28]$.

For instance, Elder and Krishna [27] depicted what happens during mental simulation: An automatic form of mental imagery, used to remind previous sensory experiences. Previous studies demonstrate that mental simulation facilitates interaction with a new (food) product and help people to decide whether they would like to eat it or not [27-30]. By essence, the (imagination of the) consumption of food is multisensory. People not only recall and sometimes simulate, their past experiences visually, but they can also imagine the smell, the texture in the mouth, and the taste felt during previous consumption of that given product. Previous research has revealed that viewing pictures of appetizing food not only activates the visual cortex, but also brain areas that code how food actually tastes (the insula/operculum), and the reward values of tasting it (the orbitofrontal cortex) [31]. Similarly, reading words like "cinnamon" or "garlic" leads to neural activity in the primary olfactory cortex [32].

This multisensory mental imagery might have negative effects on the regulation of consumption by stimulating food craving. Indeed, visual food cues appear to be associated with a similar effect to real food on eating behavior and weight gain [33]. Mental simulation has a motivational function. It facilitates the preparation of subsequent actions as illustrated by activity in premotor brain areas and sometimes in muscles - that are interpreted as the preparation of the movements that one would make to grab food and eat it [26]. The mental simulation of eating is modulated by one's hunger state, and the energetic content of the food to be consumed. These modulations are associated with increased activation in brain areas found to participate in the processing of taste and reward (i.e. the bilateral posterior fusiform gyrus, the left lateral orbitofrontal cortex, and the left middle insula) [34]. Such a notion would be consistent with one of Elder and Krishna's [27] findings that for people with higher mental imagery scores (i.e. who indicate to have more pictures of them using the product in mind), purchase intentions increased. Recently, Christian, Miles, Kenyeri, Mattschey, and Macrae [35] have demonstrated that imagining unhealthy food consumption from a first-person perspective (i.e., in which people visualize events through their own eyes), increases sensory representation of taste, actual consumption, and willingness to pay for unhealthy food. Given that food pictures and videos shared on social media are generally taken from a first person perspective, they are likely to exacerbate the desire to get the food.

Multisensory mental simulation also affects obese individuals more intensively. Indeed, obese individuals exhibit a greater increase in neural activation in response to food, especially for high-calorie products. This effect is also observed during satiety states, i.e. after obese individual have eaten [36]. Moreover, previous studies have shown that people reporting more sensory simulations of eating are more prone to anchor their consumption on the product units they see on the packaging. Hence, eating more after seeing a package with more product units displayed on package (e.g., four cookies vs. seven cookies) $[4,37]$. Thus, food porn appears prima facie to have a negative effect on food behavior by stimulating the desire for food consumption and by potentially setting a standard for food quantities, preference, and choices. However, food porn does not necessarily have to promote high-calorie food, it can also help consumers to regulate their consumption.

\section{Multisensory mental imagery and satiety}

If multisensory mental imagery can stimulate food craving, it may also produce satiety [38]. Indeed, satiety is driven both by an internal homeostatic signal indicating that physiological limits have been reached; and by a cognitive component linked to sensory adaptation and habituation $[39,40]$. Since simulation of consumption activates partially the same brain areas that are recruited during consumption, they can produce similar sensations, as the feelings of fullness after eating a large quantity of food $[28,29,38,41]$. For instance, when people are asked to imagine eating an M\&M's candy, and repeat this 30 times (versus just 3 times) subsequent consumption of these candies is significantly reduced because the desire to eat M\&M's decreased [41].

This effect can also happen implicitly, that is without having to ask individuals to actively imagine they are consuming food products [38]. Larson et al. have shown that viewing a sequence of 60 (vs. 20) pictures of food on a screen decreases people's enjoyment during consumption [39]. This effect has been confirmed at the cerebral level [42]: Toepel et al. demonstrated that viewing a portion judged as "too big" is associated with lesser activity in areas associated with attention and reward valuation (the inferior parietal lobule, superior temporal gyrus, and mid-posterior cingulate gyrus) compared to the sight of the portion judged as "ideal" [42].

This implicit effect of imagining eating a large quantity of food suggests that viewing food pictures on social media can have also positive effects on health behavior. Contrary to food advertisement on TV that are watched passively, people actively spend more and more time viewing food pictures and videos on digital media. For this reason, this active exposition to food pictures is more likely to stimulate multisensory mental imagery. Thus, by increasing the time and/or repeating food item presentation on social media, health prevention might produce satiety from visual images by activating a part of the 
brain areas that are recruited during consumption, leading to reduce the food craving and consumption.

\section{Multisensory mental imagery and food portion size}

Imagining the multisensory experience of eating a large quantity of food can have positive effects on consumption regulation by reducing the portion size effect (eating more food from larger food portions than smaller food portions) [43]. Petit et al. [43] reduced the portion size effect, by asking participants to imagine the sensory experience of eating the entire portion of food explicitly before selecting food inside a portion. The participants in this condition did not change their food selection according to the size of the portion (smaller vs. larger). By contrast, those participants in the control condition selected more food in the larger food portion than in the smaller food portion. These results suggest that imagining the experience of eating the whole portion might lead people to adjust their food intake behavior as a function of their hunger rather than food portion norms.

Simulating the multisensory experience can also enhance enjoyment and willingness to pay for a smaller portion of food [25]. In this study, participants were asked to vividly imagine the multisensory experience of eating three unhealthy food products prior to choosing a portion size of another unhealthy food. Cornil and Chandon found that the multisensory mental imagery led people to choose smaller portions and expected more pleasure from these portions. Thus, multisensory mental imagery of food consumption can turn to be an effective way for consumers to control their food intake more easily, without reducing their enjoyment. It would be interesting to test whether sending a video promoting the multisensory experience of eating an appetizing food to consumers before they eat, could lead them to enjoy it more and reduce their consumption.

\section{Multisensory mental imagery and healthy food choices}

A recent meta-analysis showed that obese individuals present more activation in gustatory and reward-related brain areas when they see appetizing food pictures (of high calorie food), than lean individuals [36]. These results suggest that people with higher BMI may have more reenactment of their past consumption experiences and expect more enjoyment from the consumption when they see food pictures and videos in digital environments. Moreover, when they have to inhibit urges to eat food, compared to lean individuals, obese people have significantly less activity in self-control-related brain areas (i.e. the left dorsolateral prefrontal cortex, DLPFC) and in the orbitofrontal cortex, a reward-related brain area [44]. Significantly, lower activity in the left DLPFC was found compared to non-obese individuals in response to viewing food pictures [45]. These studies suggest that when people see food pictures on Instagram, their desire for food may be exacerbated, their capacity of self-control reduced, leading them to succumb more easily to the temptation of consuming it.

However, a functional neuroimaging study investigated whether imagining the multisensory pleasure of eating healthy food could modulate activity in brain networks used to exercise self-control, and whether it increases healthy food choices amongst people with high BMI compared to lower BMI ones [46]. In this context individuals with a higher BMI had more activity in self-control (the inferior frontal gyrus), gustatory (the insula), and reward-related (the orbitofrontal cortex) brain areas during food choices, as compared to a control condition. They also made healthier food choices. By contrast, when their attention was drawn to the health benefits, individuals with a higher BMI exhibited less activity in gustatory and reward-related

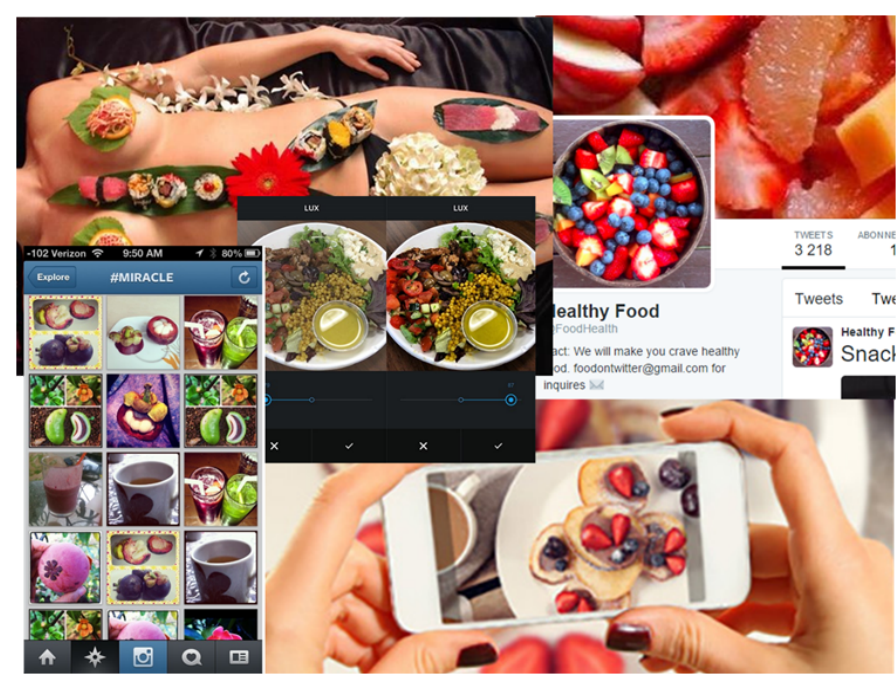

Figure 2. Healthy food porn on social media.
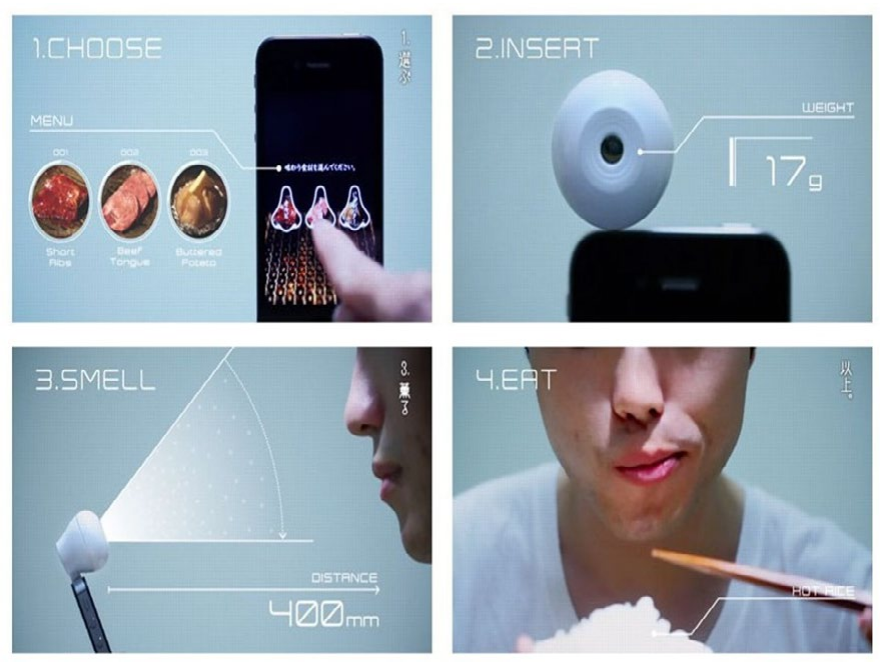

Figure 3. Multisensory mental imagery and digital environment. Scentee and Hana yakiniku Set [50].

brain areas (the inferior frontal operculum, the insula) compared to a control condition. Thus, we can expect that focusing people's attention on appetizing healthy food pictures rather than unhealthy food pictures on social network might have positive effects on self-control and food choice.

Given that simulating food consumption from a first-person perspective increases mental representation about the taste and willingness to pay to get the food [35], sharing videos and pictures of healthy food on social media could help people to make healthy food choice. By contrast, imagining food consumption from a thirdperson perspective (i.e., in which people see themselves embedded in an event, as if from an external point of view) has be shown to reduce food intake and willingness to pay [35]. Thus, using this perspective for unhealthy food in social media, could also help people to reduce their consumption of unhealthy food products. Moreover, food porn does not only promote junk food. For instance, Food Health on Twitter publishes appetizing pictures of healthy food and has more than $300 \mathrm{k}$ followers. Thus, health prevention would be well inspired by 


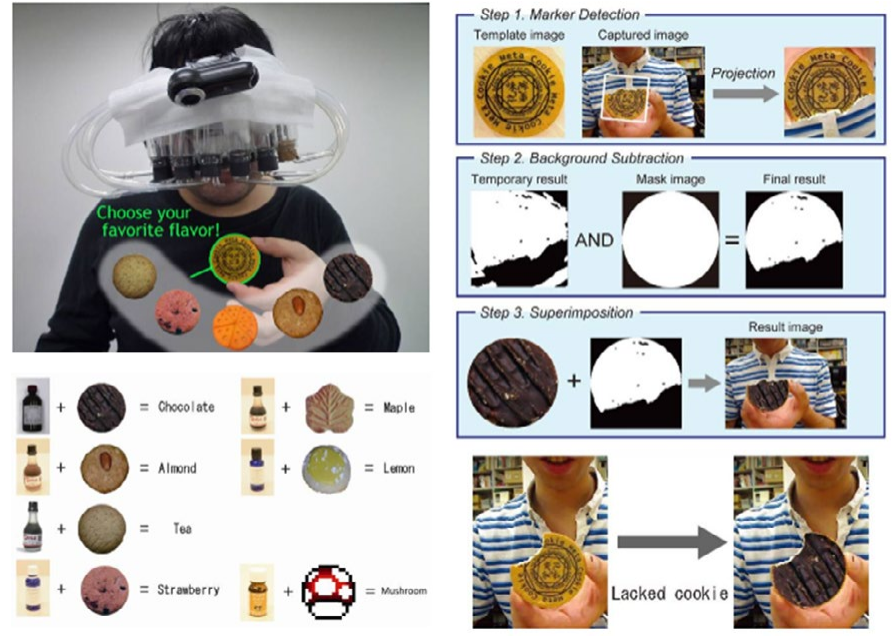

Figure 4. Augmented Reality (AR) device- MetaCookie+. MetaCookie+ adapted from Narumi et al. [51].
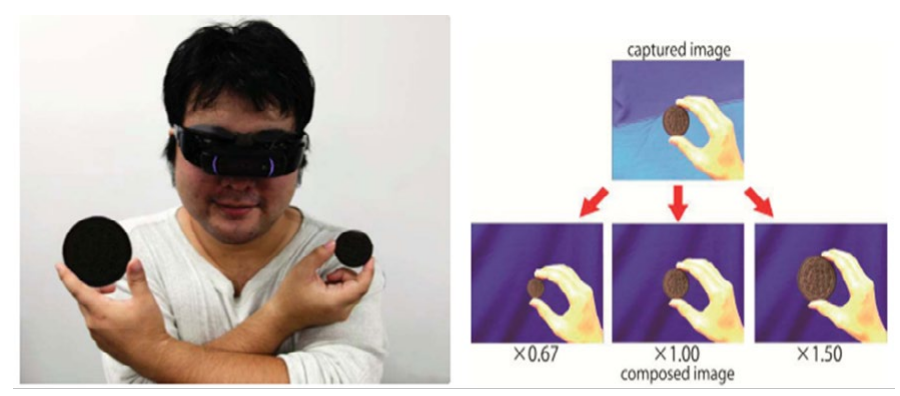

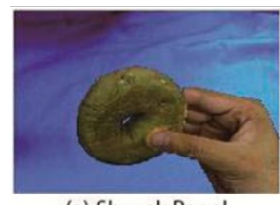

(a) Shrunk Bagel

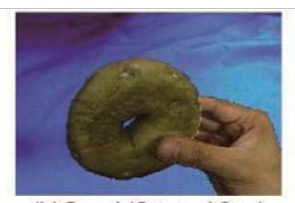

(b) Bagel (Original Size)

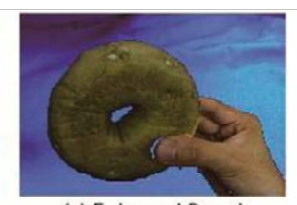

(c) Enlarged Bagel
Figure 5. AR device to create a larger food size illusion during eating. Food-volume augmented realty adapted from Narumi et al. [52].
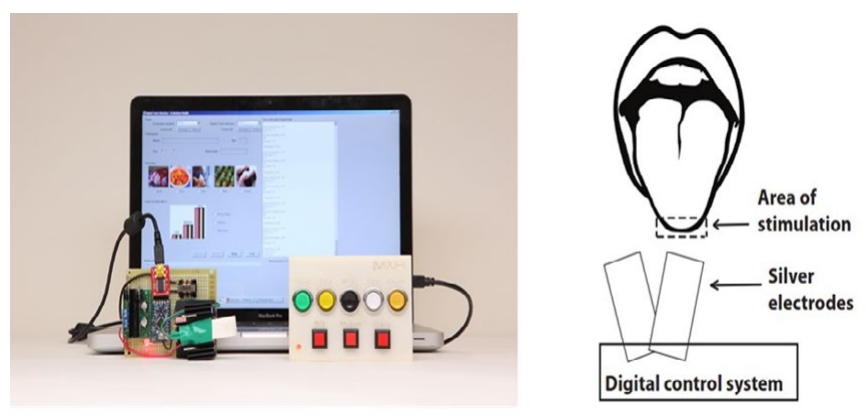

Figure 6. A system to simulate taste sensations through electrical and thermal stimulation on the tongue. Digital taste interface used in Ranasinghe et al. [54].

the new food-related trendsto promote the pleasure of eating healthy food on social media from a first-person perspective, leading to create a "healthy food porn" (Figure 2) [47].

\section{Multisensory mental imagery and digital environments}

Digital technologies has revolutionized how consumers communicate to each other, how they get information, and purchase products/services. In the context of food behavior, these technologies might be used to stimulate the multisensory mental imagery of food consumption [48], to create more enjoyment for healthy food and/or smaller food portions.

To stimulate the appetite for healthy food products, some new technologies have the potential to be game-changers. For instance, Scentee is a new olfactory display device that is connected to a mobile phone and vaporizes a scented solution stored inside [49]. This device works with an application (Hana yakiniku Set) to provide a multisensory enriched eating experience (visual, sound and smell) [50]. People can select "Short Ribs" on the app and will then see its picture, smell its odor, and hear the sound of the ribs when being grilled on a barbecue to create a more flavorful experience (Figure 3). Thus, this might be used to help people to follow a healthy meal plan.

Similarly, Narumi, Nishizaka, Kajinami, Tanikawa, and Hirose [51] created an Augmented Reality (AR) device called "MetaCookie+", to produce taste illusions by overlaying visual and olfactory information onto a real food product (Figure 4). In a study using this AR device, participants evaluated differently the taste of a same plain cookie by virtually changing its appearance and smell (e.g. chocolate, strawberry). It is therefore possible to imagine changing the aesthetic appearance and the flavor of healthy food, making the food experience a more pleasant one [15]. In another study, Narumi et al. [52] used a similar AR device to create a larger food size illusion during eating (Figure 5). By using this system, people imagined to eat a larger food portion than the real one, leading to reduce the consumption. Thus, in digital environments, AR device scan be used to stimulate the multisensory mental imagery of eating a large amount of food to produce satiety.

New technological evolutions also suggest that in the near future, it will be possible to create gustatory illusions by digital stimulation on the surface of the tongue [53-55]. Ranasinghe et al. [53] developed a system that creates taste sensations (e.g. sourness, sweetness, bitterness, saltiness) through electrical and thermal stimulation of the tongue (Figure 5). Such devices could be embedded in a spoon or a fork to simulate taste sensation during eating and therefore contribute to reducing the amount of salt or sugar used when cooking. It might be interesting to test whether these kinds of technology can be used to produce satiety, as multisensory mental simulation of food consumption does, by repeated digital taste stimulations on the surface of the tongue.

\section{Conclusions}

In the fight against obesity, it is particularly important to consider the recent evolution in food behavior. People spend less time eating and are less focused on the amount of food inside their readymeals portions. This leads them to automatically eat more in larger portions than in smaller ones. In addition, people seem to give more importance on the expected pleasure they are going to experience when consuming food as suggested by the incredible number of food-related content shared on social media. People publish, share, and comment on pictures of appetizing foods, leading to an increase of their food craving and consumption. However, as suggested in this article, food porn could also have a positive impact on healthy food consumption. It can be used to simulate the consumption of a large quantity of food 
to produce satiety, or make more enjoyable healthy food choices to facilitate self-control. Crowd sourced digital cooking publications and communities (such as FeedFeed.info and its almost 700k followers on Instagram) curate content from kitchens around the world and should serve as inspiration for public authorities who want to impact the food behavior of people and promote healthier lifestyles [47].

Finally, recent developments in new technologies suggest that food social networks will not be limited to visual stimulation in the future. It might very well include smell and taste stimulations. We have tried to highlight that this technological evolution and its behavioral consequences could benefit the regulation of food intake and, by extension, the fight against obesity. A multiple stakeholder approach involving collaborative efforts of policy makers, nutritionists, academics, consumers associations and the industry will allow leveraging digital platforms and environments to promote healthy food behaviors and improve people's health and wellbeing [56].

\section{Acknowledgments}

We thank Michael Herrera for advice throughout the drafting process.

\section{References}

1. http://www.oecd.org/health/Obesity-Update-2014.pdf

2. Popkin BM (2002) An overview on the nutrition transition and its health implications: the Bellagio meeting. Public Health Nutr 5: 93-103. [Crossref]

3. Chandon P, Wansink B (2011) Is food marketing making us fat? A multi-disciplinary review. FnTMKG5: 113-96.

4. Rolls BJ, Morris EL, Roe LS (2002) Portion size of food affects energy intake in normal-weight and overweight men and women. Am J Clin Nutr 76: 1207-1213.

5. Wansink B (2004) Environmental factors that increase the food intake and consumption volume of unknowing consumers. Annu Rev Nutr 24: 455-479. [Crossref]

6. Zlatevska N, Dubelaar C, Holden SS (2014) Sizing up the effect of portion size on consumption: A meta-analytic review. J Marketing 78: 140-154.

7. Birch LL, Mc Phee L, Shoba BC, Steinberg L, Krehbiel R (1987) Clean up your plate: Effects of child feeding practices on the conditioning of meal size. Learn Motiv 18: 301-317. doi:10.1016/0023-9690(87)90017-8

8. Geier AB, Rozin P, Doros G (2006) Unit bias. A new heuristic that helps explain the effect of portion size on food intake. Psychol Sci 17: 521-525. [Crossref]

9. Capps O, Tedford JR, Havlicek J (1985) Household demand for convenience and nonconvenience foods. Am J of Agr Econ 67: 862-869.

10. Hamrick KS, Andrews M, Guthrie J, Hopkins D, McClelland K (2011) How much time do Americans spend on food. United States Department of Agriculture, Economic Research Service 86:1-58

11. Howard S, Adams J, White M (2012) Nutritional content of supermarket ready meals and recipes by television chefs in the United Kingdom. Cross sectional study. BMJ: Brit Med J 345: e7607.

12. Moss M (2013) Salt, sugar, fat: How the food giants hooked us. W.H. Allen: St Ives, UK.

13. Smith LP, Ng SW, Popkin BM (2013) Trends in US home food preparation and consumption: analysis of national nutrition surveys and time use studies from 19651966 to 2007-2008. Nutr J 12: 45. [Crossref]

14. McBride AE (2010) Food porn. Gastronomica (Berkeley Calif) 10: 38-46. [Crossref]

15. Spence C, Okajima K, Cheok AD, Petit O, Michel C (2015) Eating with our eyes: From visual hunger to digital satiation. Brain Cogn. [Crossref]

16. https://www.instagram.com/goodfoodau/

17. http://linecorp.com/en/pr/news/en/2016/1236

18. Bellman A (2004) Ready, steady, look. The Age, Epicure.

19. deSolier I (2005) TV dinners: Culinary television, education and distinction. Continuum:
Journal of Media \& Cultural Studies 19: 465-481.

20. Prince R (2014) How we're fed 434 hours of TV cookery a week - But the more they show, the less we cook. Daily Mail Online.

21. Ray K (2007) Domesticating cuisine: Food and aesthetics on American television. Gastronomica 7: 50-63.

22. Boulos R, Vikre EK, Oppenheimer S, Chang H, Kanarek RB (2012) ObesiTV: how television is influencing the obesity epidemic. PhysiolBehav 107: 146-153. [Crossref]

23. Bodenlos JS, Wormuth BM (2013) Watching a food-related television show and caloric intake. A laboratory study. Appetite 61: 8-12. [Crossref]

24. Petit O, Basso F, Huguet P, Plassmann H, Oullier O (2011) [Food behaviour and obesity: insights from decision neuroscience]. Med Sci 27: 1000-1008.

25. Cornil Y, Chandon P (In press). Pleasure as a substitute for size: How multisensory imagery can make people happier with smaller food portions. J Marketing Res.

26. Jeannerod M (2001) Neural simulation of action: a unifying mechanism for motor cognition. Neuroimage 14: S103-109. [Crossref]

27. Elder RS, Krishna A (2012) The visual depiction effect in advertising: Facilitating embodied mental simulation through product orientation. $J$ Consum Res 38: 988-1003.

28. Petit $\mathrm{O}$, Velasco C, Cheok AD, Spence C (in press) Consumer sensory neuroscience in the context of food marketing. In Proceedings of the 12th International Conference on Advances in Computer Entertainment Technology, $A C E$.

29. Barsalou LW (2008) Grounded cognition. Annu Rev Psychol 59: 617-645.

30. Schlosser AE (2003) Experiencing products in the virtual world: The role of goal and imagery in influencing attitudes versus purchase intentions. J Consum Res 30: 184-198.

31. Simmons WK, Martin A, Barsalou LW (2005) Pictures of appetizing foods activate gustatory cortices for taste and reward. Cereb Cortex 15: 1602-1608. [Crossref]

32. González J, Barros-Loscertales A, Pulvermüller F, Meseguer V, Sanjuán A, et al (2006) Reading cinnamon activates olfactory brain regions. Neuroimage 32: 906-912. [Crossref]

33. Boswell RG, Kober H (2016). Food cue reactivity and craving predict eating and weight gain: a meta-analytic review. Obes 17: 159-177.

34. van der Laan LN, de Ridder DT, Viergever MA, Smeets PA (2011) The first taste is always with the eyes: a meta-analysis on the neural correlates of processing visual food cues. Neuroimage 55: 296-303. [Crossref]

35. Christian BM, Miles LK, Kenyeri ST, Mattschey J, Macrae CN (2016) Taming Temptation: Visual Perspective Impacts Consumption and Willingness to Pay for Unhealthy Foods. J Exp Psychol-Appl.

36. Pursey KM, Stanwell P, Callister RJ, Brain K, Collins CE, Burrows TL (2014) Neural responses to visual food cues according to weight status: A systematic review of functional magnetic resonance imaging studies. Front Nutr 1: 7.

37. Madzharov AV, Block LG (2010) Effects of product unit image on consumption of snack foods. J Consum Psychol 20: 398-409.

38. Galak J, Redden JP, Kruger J (2009) Variety amnesia: Recalling past variety can accelerate recovery from satiation. J Consum Res 36: 575-584.

39. Larson J, Redden JP, Elder R (2014) Satiation from sensory simulation: Evaluating foods decreases enjoyment of similar foods. J Consum Psychol 24: 188-194.

40. Redden JP, Haws KL (2013) Healthy satiation: The role of decreasing desire in effective self-control. J Consum Res 39: 1100-1114.

41. Morewedge CK, Huh YE, Vosgerau J (2010) Thought for food: imagined consumption reduces actual consumption. Science 330: 1530-1533. [Crossref]

42. Toepel U, Bielser ML, Forde C, Martin N, Voirin A, et al. (2015) Brain dynamics of meal size selection in humans. Neuro Image 113: 133-142.

43. Petit O, Spence C, Velasco C, Woods A, Cheok AC (Rev). Changing the influence of portion size on consumer behavior via mental imagery.

44. Tuulari JJ, Karlsson HK, Hirvonen J, Salminen P, Nuutila P, et al. (2015) Neural circuits for cognitive appetite control in healthy and obese individuals: an fMRI study. PLoS One 10: e116640. [Crossref]

45. Brooks SJ, Cedernaes J, Schioth HB (2013) Increased prefrontal and parahippocampal activation with reduced dorsolateral prefrontal and insular cortex activation to food images in obesity: a meta-analysis of fMRI studies. PloS One 8: e60393. 
46. Petit O, Merunka D, Anton JL, Nazarian B, Spence C, et al. (under revision). Health and Pleasure in Dietary Food Choice: Individual Differences in the Brain's Value System.

47. Petit O, Basso F, Merunka D, Spence C, Cheok AD, Oullier O (in press) Pleasure and the control of food intake: An embodied cognition approach to consumer selfregulation. Psychol \& Market.

48. Petit O, Cheok AD, Spence C, Velasco C, Karunanayaka KT (in press) Sensory Marketing in Light of New Technologies. In Proceedings of the 12th International Conference on Advances in Computer Entertainment Technology, $A C E$.

49. Braun MH, Cheok AD (In press) Using Scent Actuation For Engaging User Experiences. In Proceedings of the 12th International Conference on Advances in Computer Entertainment Technology, $A C E$.

50. http://scentee.com/apps/hanayakiniku/

51. Narumi T, Nishizaka S, Kajinami T, Tanikawa T, Hirose M (2011). Augmented reality flavors: gustatory display based on edible marker and cross-modal interaction. In
Proceedings of the SIGCHI Conference on Human Factors in Computing Systems ACM 93-102.

52. Narumi T, Ban Y, Kajinami T, Tanikawa T, Hirose M (2012) Augmented perception of satiety: controlling food consumption by changing apparent size of food with augmented reality. In Proceedings of the SIGCHI Conference on Human Factors in Computing Systems. ACM 109-118.

53. Cruz A, Green BG (2000) Thermal stimulation of taste. Nature 403: 889-892.

54. Ranasinghe N, Cheok AD, Gopalakrishnakoned HN, Petit O (Submitted). Digital Taste Interface: An Electrical and Thermal Control System for Virtual Sensation of Taste.

55. http://www.dailymail.co.uk/sciencetech/article-3514391/Who-needs-seasoningPrototype-electric-fork-SHOCKS-tongue-stimulate-taste-salt.html

56. World Economic Forum (2006) Digital Media and Society Implications in a Hyperconnected era, Report.

Copyright: (2016 Petit O. This is an open-access article distributed under the terms of the Creative Commons Attribution License, which permits unrestricted use, distribution, and reproduction in any medium, provided the original author and source are credited. 